Revista lus et Praxis, Año 22, № 2, 2016, pp. 513 - 528

ISSN 0717 - 2877

Universidad de Talca - Facultad de Ciencias Jurídicas y Sociales

Modelos argumentativos y sentido de justicia transicional en Colombia en la Sentencia C-579 de 2013

Nelson Jair Cuchumbé Holguín - Sergio Molina Hincapié

Colaboración recibida el 20 de diciembre y aprobada el 15 de mayo de 2016

\title{
Modelos argumentativos y sentido de justicia transicional en Colombia en la Sentencia C-579 de $2013^{*}$
}

\author{
ARGUMENTATIVE MODELS AND SENSE OF TRANSITIONAL JUSTICE \\ in Colombia IN the JUdGment C-579 of 2013
}

\author{
Nelson Jair Cuchumbé Holguín ** \\ Sergio Molina HinCAPIÉ $E^{* * *}$
}

\begin{abstract}
RESUMEN
En el presente trabajo se sostiene que la obligación estatal de armonizar la justicia transicional con los deberes propios del derecho internacional y la flexibilización del sistema de justicia penal representan los dos sentidos de justicia transicional privilegiados en los modelos argumentativos empleados por algunos de los partícipes de la Sentencia C-579 de 2013. Para legitimar esta aserción, se comienza por describir los elementos y las características que estructuran el modelo argumentativo utilizado por los demandantes y la experta de Amnistía Internacional en la Sentencia C-579 de 2013. A continuación, se presentan los elementos y rasgos que configuran el modelo argumentativo empleado por Alejandro Aponte y los magistrados de la Corte Constitucional en el proceso de demanda del Acto Legislativo 01 de 2012. Luego se identifican, a partir de esas descripciones, los sentidos de justicia transicional privilegiados por esos partícipes en dicha sentencia con la finalidad de precisar su posible armonía con los principios de paz y justicia consagrados en la Constitución Política de 1991. Por último, se concluye que los promotores de la inexequibilidad privilegiaron un sentido normativo de la justicia transicional y acudieron a un enfoque prescriptivo que antepone al Estado la necesidad de investigar, juzgar y eventualmente sancionar los casos de vulneraciones graves a los derechos humanos como condición ineludible para la consolidación del Estado social y democrático de derecho. Y los defensores de la exequibilidad honraron un sentido de flexibilización de la justicia transicional y recurrieron a una perspectiva contextual que reconoce la importancia de aplicar la justicia acorde con las circunstancias actuales del conflicto interno y la pretensión de la culminación negociada del
\end{abstract}

\footnotetext{
* Artículo consecuencia de la investigación "Argumentaciones y producción de un sentido de justicia transicional: realización del modelo de Estado privilegiado en la Constitución Política de 1991". Investigación adelantada por el grupo "Hermes" (Colciencias, Categoría A) y financiada por la Vicerrectoría de Investigaciones de la Universidad del Valle (Cali, Colombia).

** Profesor del Departamento de Filosofía de la Universidad del Valle (Cali, Colombia). Doctor en Humanidades, Universidad delValle (Cali, Colombia).Correo electrónico: nelson.cuchumbe@correounivalle. edu.co.

*** Abogado y estudiante Licenciatura en Filosofía de la Universidad del Valle (Cali, Colombia). Correo electrónico: sergio.molina.hincapie@correounivalle.edu.co.
} 
mismo. Independientemente de este matiz diferenciador, ambos sentidos son compatibles con los principios de paz y justicia consagrados en la nueva Carta Magna.

ABSTRACT

This paper argues that obligation to harmonize State Justice transitional with the duties of the international law and the criminal justice system more flexible, represent the two senses of transitional justice privileged in the argumentative models used by some holders of the 2013 judgment C-579. To legitimize this assertion, begins by describing the elements and characteristics that structure the argumentative model used by plaintiffs and expert of Amnesty International in the judgment C-579 from 2013. Below, are the elements and features that shape the argumentative model employed by Alejandro Aponte and the judges of the Constitutional Court in the process of the legislative act 01 of 2012 demand. Then, identify, from these descriptions, the senses of transitional justice privileged by those participants in this sentence in order to clarify their possible harmony with the principles of peace and justice enshrined in the political Constitution of 1991. Finally, it is concluded that promoters of the inexequibilidad privileged a normative sense of transitional justice and attended a prescriptive approach that puts the State the need to investigate, judge and eventually punish cases of serious violations to human rights as unavoidable condition for the consolidation of the social and democratic State of law. And defenders of the constitutionality was honoured a sense of relaxation of transitional justice and resorted to a contextual perspective that recognizes the importance of applying the justice commensurate with the circumstances of the conflict and the negotiated culmination of the same claim. Independent of this differentiating nuance both directions are compatible with the principles of peace and justice enshrined in the new Constitution.

\section{Palabras Clave}

Modelo argumentativo, Justicia transicional, Sentido de Flexibilización, Sentido Normativo

KEYWORDS

Argumentative model, Transitional justice, Sense of flexibility, Regulatory sense

\section{Introducción}

El asunto de la producción de un marco jurídico viabilizador de la consecución de la paz en los Estados constitucionales sometidos a conflictos internos hace que del amplio espectro de los procesos jurídico-políticos quede en un primer plano la legitimación de un sentido de justicia transicional. Desde el punto de vista de la argumentación jurídica se ha indicado que toda legitimación supone discusiones diferenciadas según formas de argumentación. Un caso que ilustra ese asunto es la discusión en Colombia sobre el "Marco jurídico para la paz". Tras más de medio siglo de conflicto armado en Colombia entre Estado y guerrillas de las FARC-EP, en la actualidad se efectúa un proceso de diálogo orientado hacia su culminación negociada. Este proceso exigió generar y legitimar un sentido de justicia transicional que sirviera como trasfondo constitucional para regular la reinserción de los miembros de esa guerrilla a la vida civil y garantizar los derechos de las víctimas. Ambas exigencias son constitutivas del Acto Legislativo 01 de 2012, mediante el cual se institucionalizó el artículo transitorio 66 en la Constitución Política de 1991. 
En dicho artículo se privilegió un sentido de justicia transicional con el que se pretendió armonizar la tensión entre el principio de la paz y el principio de la justicia. Sin embargo, dicho Acto Legislativo fue demandado por algunos ciudadanos como inexequible ante la Corte Constitucional, pues consideraron que el sentido de justicia transicional legitimado promueve en sí mismo la impunidad respecto a las violaciones graves de los derechos humanos y del Derecho Internacional Humanitario (DIH). Esta demanda se resolvió por la Corte Constitucional mediante Sentencia C-579 de 2013, en la que participaron actores con diferentes argumentos respecto a la exequibilidad o no de la norma demandada; argumentos con los que se intentó posicionar una decisión acorde con un sentido de justicia transicional estimado por cada actor como el más loable.

Esta acción de inconstitucionalidad contra el Acto Legislativo 01 de 2012 constituyó el eslabón básico de la discusión entre promotores de la inexequibilidad y defensores de la exequibilidad del sentido de justicia transicional. Los promotores de la inconstitucionalidad rechazaron las expresiones lingüísticas "máximos", "cometidos de manera sistemática" y "todos los" contenidas en ese Acto, porque consideraron que sustituyen uno de los pilares fundamentales de la Constitución: el deber del Estado colombiano de investigar, juzgar y en su caso sancionar todas las violaciones graves de los derechos humanos y las infracciones graves al DIH. Contrario a esto, los defensores de la constitucionalidad acogieron tales expresiones impugnadas como necesarias, pues estimaron que flexibilizan el sistema de justicia al permitir centrar la investigación, el juzgamiento y la eventual sanción de violaciones sistemáticas de derechos humanos en casos emblemáticos y prometedores, lo que evitaría el colapso de tal sistema y facilitaría las condiciones para que los responsables de crímenes atroces participen del actual proceso de paz entre Estado colombiano y FARC-EP. Una y otra argumentación fue empleada con la intención de legitimar, respectivamente, un sentido de justicia transicional compatible con los principios de justicia y paz consagrados en la Constitución Política de 1991.

La tentativa de ofrecer buenas razones para legitimar un sentido de justicia transicional se refleja en la Sentencia C-579 de 2013 y exigió, por ejemplo, a demandantes, expertos invitados y magistrados de la Corte Constitucional organizar y presentar argumentaciones sobre la corrección de sus aserciones respecto a la constitucionalidad o no del sentido de justicia transicional institucionalizado en el Acto Legislativo 01 de 2012. La actividad de organizar y presentar argumentaciones implicó seguir procedimientos de validación fijados en el campo de la argumentación jurídica: uso de un modelo argumentativo, empleo de unas premisas y técnicas discursivas ${ }^{1}$, y seguimiento de un tipo de

1 Ver Perelman y Olbrechts-Tyteca (1989). 
razonamiento jurídico para la legitimación de fallos motivados que fijan solución a las controversias jurídicas ${ }^{2}$. El estudio de la argumentación aplicada en el campo del derecho admite centrarse en alguno de esos procedimientos de validación. De acuerdo con Stephen Toulmin ${ }^{3}$ toda forma de argumentación puede analizarse de modo adecuado refiriéndose, por ejemplo, al uso de un modelo argumentativo en la interacción discursiva.

En este contexto temático, emerge la siguiente pregunta: ¿qué sentido de justicia transicional se privilegió en Colombia mediante los modelos argumentativos utilizados por algunos de los promotores de la inexequibilidad y defensores de la exequibilidd del Acto Legislativo 01 de 2012 en la Sentencia C-579 de 2013? Obligación estatal de armonizar la justicia transicional con los deberes propios del derecho internacional y flexibilización del sistema de justicia penal, representan los dos sentidos de justicia transicional privilegiados en los modelos argumentativos empleados por ciertos partícipes de la Sentencia C-579 de 2013. Para mostrar la fuerza de validez de esta aserción se describe los elementos y las características que estructuran el modelo argumentativo utilizado por los demandantes y la experta de Amnistía Internacional en la Sentencia C-579 de 2013; se presenta los elementos y rasgos que configuran el modelo argumentativo empleado por Alejandro Aponte y los magistrados de la Corte Constitucional en el proceso de acción de inconstitucionalidad del Acto Legislativo 01 de 2012; y se identifica a partir de esas descripciones los sentidos de justicia transicional privilegiados por esos partícipes en dicha Sentencia con la finalidad de precisar su posible armonía con los principios de justicia y paz consagrados en la Constitución Política de 1991.

\section{Elementos del modelo argumentativo: demandantes y experta de Amnistía Internacional}

Los magistrados de la Corte Constitucional colombiana al legitimar en la Sentencia C-579 de 2013 la decisión de que el inciso cuarto del artículo 1 del Acto Legislativo 01 de 2012 es exequible, revistieron de fuerza de cosa juzgada dicho inciso. En virtud de esta decisión no sólo se institucionalizó un sentido de justicia transicional, sino que también se culminó con uno de los procesos de discusión suscitados en Colombia sobre el marco jurídico para la paz. En este proceso participaron por ejemplo demandantes, expertos invitados y magistrados de la Corte Constitucional; participación que les implicó seguir procedimientos de validación argumentativa orientados hacia el posicionamiento de sus

2 Ver AtienZa (2005). También ver Alexy (1997).

3 Ver Toulmin (2007), cap. III. 
interpretaciones en la discusión. Dicho proceso de discusión se dinamizó a partir de la tensión argumentativa entre los promotores ${ }^{4}$ de la inexequibilidad y los defensores ${ }^{5}$ de la exequibilidad del sentido de justicia transicional. Dos de los representantes del primer grupo fueron (a) demandantes y (b) Guadalupe Marengo en calidad de experta invitada de Amnistía Internacional. Y dos de los exponentes del segundo grupo fueron (a) Alejandro Aponte como experto invitado y (b) los magistrados de la Corte Constitucional colombiana.

a) La tesis de los demandantes radicó en aseverar que el artículo 1 del Acto Legislativo 01 de 2012 es inconstitucional. Aserción que es de tipo causal, pues, según este grupo de actores, la institucionalización del contenido material de ese Acto produce como consecuencia la sustitución del compromiso estatal de investigar, juzgar y en su caso sancionar graves vulneraciones a los derechos humanos y al DIH. Dicha tesis fue apoyada teniendo en cuenta tres evidencias normativas: 1) el Acto Legislativo autoriza al Congreso para fijar criterios de selección sobre qué casos de violación de derechos humanos y DIH deben ser investigados, juzgados y eventualmente sancionados con el propósito de que los esfuerzos investigativos se dirijan hacia los "máximos responsables" de tales trasgresiones; 2) el Acto Legislativo faculta al Congreso para que mediante ley estatutaria autorice la renuncia condicionada a la persecución penal de los casos no seleccionados, y 3) el Acto Legislativo aprueba que el Estado sólo debe investigar a los máximos responsables de crímenes de guerra cometidos de manera sistemática, creando así una nueva regla ${ }^{6}$. Los garantes empleados para entrelazar esa aserción con dichas evidencias fueron: el artículo 1.1 de la Convención Americana sobre Derechos Humanos prescribe que los Estados Parte tienen el deber de respetar y garantizar el libre y pleno ejercicio de los derechos humanos, y el artículo 2 de la Constitución Política de 1991 establece que uno de los fines del Estado es respetar y garantizar los derechos fundamentales de todas las personas residentes en Colombia.

Ambas garantías se respaldaron, respectivamente, a partir de la interpretación efectuada por la Corte Interamericana de Derechos Humanos sobre la norma

\footnotetext{
4 Este modo de interpretación fue promovido por los ciudadanos demandantes (Gustavo Gallón Giraldo, Fátima Esperanza Calderón, Mary de la Libertad Díaz Márquez y Juan Camilo Rivero Rugeles) y algunos expertos invitados ofrecen argumentos susceptibles de ser usados a favor de la posición de los demandantes (Natalia Springer, Human Rights Watch y Amnistía Internacional).

5 Como bien se sabe, esta forma de comprensión fue apoyada por algunos expertos invitados (Iván Orozco Abad y Alejandro Aponte Cardona) y los magistrados de la Corte Constitucional (Jorge Iván Palacio, María Victoria Calle, Mauricio González, Luis Guillermo Guerrero, Alberto Rojas, Nilson Pinilla, Gabriel Eduardo Mendoza, Jorge Ignacio Pretelt y Luis Ernesto Vargas).

6 "El Estado colombiano no está obligado a investigar y juzgar todas las conductas que constituyan crímenes de guerra, sino tan sólo aquellas conductas que constituyan crímenes de guerra cometida de manera sistemática". Comisión Colombiana de JuRISTAS (2012), p. 4.
} 
instituida en el artículo 1.1 de la Convención y la interpretación de la Corte Constitucional en lo referido a los fines del Estado colombiano. Apoyados en la interpretación de los jueces de la Corte Interamericana, los demandantes reafirmaron que el artículo 1.1 de la Convención Interamericana de Derechos Humanos contiene la norma según la cual es deber de los Estados Partes "organizar todo el aparato gubernamental y, en general, todas las estructuras a través de las cuales se manifiesta el ejercicio del poder público, de manera tal que sean capaces de asegurar jurídicamente el libre y pleno ejercicio de los derechos humanos. Como consecuencia de esta obligación los Estados deben prevenir, investigar y sancionar toda violación de los derechos reconocidos por la Convención y procurar, además, el restablecimiento, si es posible, del derecho conculcado y, en su caso, la reparación de los daños producidos por la violación de los derechos humanos" ${ }^{\prime \prime}$.

Y respaldados en la interpretación de los magistrados de la Corte Constitucional colombiana sobre el artículo 2 de la Constitución Política de 1991, los demandantes aseveraron que es deber del Estado investigar, juzgar y sancionar todos los hechos que constituyan una trasgresión grave a los derechos fundamentales, incluidas las infracciones graves al $\mathrm{DIH}^{8}$. Se trata de dos interpretaciones constitutivas de la jurisprudencia internacional y nacional que son, respectivamente, orientadoras de los jueces en sus decisiones y criterio auxiliar de la justicia.

Aserción, evidencias, garantes y respaldos empleados por los demandantes estuvieron complementados con el uso de un cualificador modal y una posible refutación. El cualificador se manifiesta a través del modal "necesariamente", que expresó un alto grado de intensidad de la aserción defendida:

"Al autorizar la renuncia a la investigación y el juzgamiento de responsables de violaciones graves de DDHH e infracciones graves al DIH se afecta, necesariamente $^{9}$, tal deber general de investigar, pues quedaría a disposición del Congreso autorizar la renuncia a lo que hasta hoy había sido un deber jurídico indisponible"10.

Y la posibilidad de refutación se refleja en la afirmación de que la Constitución no contiene normas intangibles. En palabras de los demandantes:

"No puede pensarse que estamos asumiendo que existe un elemento intangible dentro de la Constitución que esté por encima del poder constituyente

7 Corte Interamericana de Derechos Humanos, caso Velásquez Rodríguez vs. Honduras (1988).

8 Comisión Colombiana de Juristas (2012), p. 4.

9 Cursivas nuestras.

10 Comisión Colombiana de Juristas (2012), p. 27. 
derivado, ya que consideramos que sí podrá modificarse, siempre y cuando se respeten los derechos de las víctimas al acceso a la administración de justicia y a la verdad, la justicia y la reparación"111.

Con estas descripciones realizadas se ponen de relieve los elementos que estructuran el modelo argumentativo con sus respectivos contenidos semánticos y materiales: aserción causal, datos representados en evidencias normativas, garantes constituidos por normas jurídicas internacionales y nacionales, respaldos basados en la autoridad interpretativa de los jueces de la Corte Interamericana y magistrados de la Corte Constitucional, indicador modal de alto grado de certeza y refutación referida a la intangibilidad de las normas constitucionales. Dicho modelo fue empleado por los demandantes con el fin de posicionar un sentido normativo de la justicia transicional y desplazar el sentido de flexibilización ennoblecido por los promotores de la exequibilidad del Acto Legislativo 01 de 2012.

b) La aserción de la experta de Amnistía Internacional, Guadalupe Marengo, consistió en afirmar que los Estados "no pueden sustraerse del deber de investigar, perseguir y sancionar a los responsables de los crímenes de derecho internacional aplicando leyes de amnistía o cualquiera otra norma interna, incluyendo la renuncia a la acción judicial"12. Aserción que es de tipo político, pues orienta a las autoridades públicas frente al modo en que deben actuar cuando decidan implementar un marco de justicia transicional. En este sentido, se exige a las autoridades privilegiar la armonía entre justicia transicional y obligaciones del Estado en el marco del derecho internacional. Dicha tesis política estuvo basada en la existencia de convenios de los cuales Colombia es un Estado Parte y que presuponen obligaciones de derecho internacional. Entre estos convenios que ayudaron a validar esa aserción, sobresalen: Convención para la Prevención y la Sanción del Delito de Genocidio; Convenios de Ginebra; Protocolo I adicional a los Convenios de Ginebra; Convención contra la Tortura y Otros Tratos o Penas Crueles, Inhumanos o Degradantes; Convención Interamericana para Prevenir y Sancionar la Tortura; Convención Interamericana sobre Desaparición Forzada de Personas; Convención Internacional para la protección de todas las personas contra las desapariciones forzadas, y Estatuto de Roma de la Corte Penal Internacional.

Como garante para conectar dicho conjunto de evidencias con la aserción, la experta de Amnistía Internacional empleó los artículos 26 y 27 de la Convención de Viena sobre el Derecho de los Tratados. El artículo 26 contempla

11 Comisión Colombiana de Juristas (2012), p. 25.

12 Amnistía Internacional (2013), p. 12. 
el principio pacta sunt servanda, según el cual "todo tratado en vigor obliga a las partes y debe ser cumplido por ellas de buena fe"; el artículo 27 establece que "una parte no podrá invocar las disposiciones de su derecho interno como justificación del incumplimiento de un tratado". Estas dos garantías fueron respaldadas a partir del juicio de un experto en derecho internacional y de la opinión consultiva de una corte internacional. El juicio fue proferido por el tratadista José Pastor Ridruejo, quien reafirmó que "los tratados deben observarse aunque sean contrarios al Derecho Interno de alguno de los Estados partes"13. Y la opinión consultiva fue emitida por los miembros de la Corte Internacional de Justicia, quienes confirmaron que "es un principio generalmente aceptado de derecho internacional que en las relaciones entre las Potencias contratantes de un tratado, las disposiciones de derecho interno no pueden prevalecer sobre aquellas del tratado"14.

A estos cuatro elementos descriptos, del modelo argumentativo empleado por la experta de Amnistía Internacional, se articuló un cualificador modal y una objeción. Respecto al cualificador se hizo uso del modal "necesariamente" que denota un alto grado de certeza de la aserción:

"la renuncia a la persecución penal de graves violaciones de derechos humanos realizada en virtud de los criterios de selección y priorización o de cualquier otro criterio o norma interna vulnera necesariamente ${ }^{15}$ las obligaciones de derecho internacional que pesan sobre Colombia"16.

Y en lo relativo a la objeción, se planteó como probable debilidad de la aserción el hecho de que en el Estatuto de la Corte Especial para Sierra Leona se circunscribió de manera expresa la competencia de la jurisdicción de dicha Corte sobre aquellas personas que hayan ostentando el más alto grado de responsabilidad penal individual en la comisión de crímenes de derecho internacional.

Está presentación sobre los rasgos esenciales de los elementos del modelo argumentativo deja ver una aserción de carácter político, unos datos basados en la autoridad de los tratados internacionales, una garantía cimentada en dos reglas de derecho internacional, un respaldo soportado en valoraciones normativas emitidas por especialistas, un cualificador modal que expresa un alto grado de certeza de la aserción, y una probable refutación que advierte la posibilidad de centrar los esfuerzos de investigación y juzgamiento en los máximos responsables de violaciones graves contra los derechos humanos. Modelo argumentativo utilizado con el fin de advertir que, si se acoge cualquier

13 Pastor Ridruejo (1994), p. 135.

14 Corte Internacional de Justicia (1988).

15 Cursivas nuestras.

16 Amnistía InternaCiOnal (2013), p. 12. 
criterio que admita renunciar a la persecución penal de graves violaciones de derechos humanos en el marco de una justicia transicional, se desconoce las obligaciones de derecho internacional derivadas de los convenios en los que Colombia es un Estado Parte.

\section{Elementos y sus rasgos del modelo argumentativo: Alejandro Aponte y magistrados de la Corte Constitucional colombiana}

Presentado el modelo argumentativo utilizado por los defensores de la inexequibilidad del artículo 1 numeral cuarto del Acto Legislativo 01 de 2012, se describen ahora los elementos, con sus características, que constituyen el modelo argumentativo empleado por los promotores de la exequibilidad de dicho artículo. Tal como ya se indicó, estos promotores conformaron el segundo grupo que participó de la tensión argumentativa reflejada en la Sentencia C-579 de 2013. Dos de los representantes de este grupo fueron (a) Alejandro Aponte como experto invitado y (b) los magistrados de la Corte Constitucional colombiana.

a) La aseveración del experto invitado, Alejandro Aponte, residió en ratificar que el Acto Legislativo 01 de 2012 se ajusta a los instrumentos internacionales sobre derechos humanos; razón por la cual dicho Acto debe ser considerado constitucional. Aseveración que es de tipo causal pues con ella se manifiesta que dada la correspondencia entre el Acto Legislativo y los instrumentos internacionales de derechos humanos, se produce como efecto la obligación de aceptar la constitucionalidad de tal Acto. Esta aseveración tuvo como soporte dos presupuestos normativos: 1) el Acto Legislativo contiene criterios de selección y priorización de casos para realizar la investigación, el juzgamiento y la eventual sanción de quienes presuntamente han participado en situaciones constitutivas de crímenes contra los derechos humanos y el DIH; y 2) el modelo de justicia transicional en Colombia es un caso heterodoxo, ya que su aplicación se efectúa dentro de un contexto social donde aún se presentan casos propios de un conflicto armado interno.

La conexión entre esa aseveración causal y estos soportes fue cimentada en tres garantías, representadas en un principio y dos reglas. El principio reivindica el carácter fragmentario del Derecho Penal, es decir, su imposibilidad de hacer justicia frente a todos los actos cometidos en la sociedad que constituyan delitos; carácter fragmentario que se hace más evidente cuando se investigan y juzgan vulneraciones sistemáticas de derechos humanos y DIH. Las dos reglas regulan los modos de aplicación de los criterios de selección y priorización de casos. La primera alude a los supuestos que están a la base de dichos criterios: diferenciación, focalización y redirección de la acción penal. Y la segunda regla refiere a la necesidad de acompañar tales criterios con procesos de reparación a las víctimas e identificación de la verdad de los hechos ocurridos. 
Estos tres garantes fueron respaldados por los defensores de la constitucionalidad del Acto Legislativo 01 de 2012 acudiendo a conceptos jurídicos en virtud de los cuales se valida, por una parte, la idea de que la justicia no puede ser entendida como justicia penal absoluta, pues debe entenderse que en el marco de la implementación de un sistema de justicia transicional pueden articularse otras concepciones de justicia: administrativa (reparación) y civil (restitución de tierras). Y, por otra, se legitima el supuesto de que los mecanismos de justicia penal también pueden ser diversos; esto es, al aplicar la ley penal es posible implementar mecanismos de Derecho Penal diferencial: amnistías condicionadas, disminución de la sanción penal o conceder beneficios condicionados.

Estos cuatro elementos, que configuraron el modelo argumentativo utilizado por el experto invitado, se complementaron con un cualificador modal y una refutación. En lo relativo con el cualificador se empleó la expresión modal "imposible", que enuncia un muy alto grado de certeza de la aserción causal propuesta:

"Los dilemas que enfrenta el Derecho Penal de cara a estos desafíos, no son sólo jurídicos, sino también de carácter ético-político, pues el valor ideal de la persecución, sería la persecución penal efectiva de todos y cada uno de los hechos cometidos por cada uno de los actores, independientemente de su jerarquía en el aparato criminal. No obstante, el ignominioso principio de la realidad impone su dinámica y hace aquel cometido imposible ${ }^{17}$, salvo que dicho cometido se prometa de manera puramente discursiva y meramente simbólica, de tal forma que, finalmente, se afecten de manera reiterada las expectativas de las víctimas"18.

Y en lo tocante con la refutación, se advirtió como factible la objeción según la cual el fin de los criterios de selección es, por una parte, establecer los casos que pueden ser investigados y juzgados por la jurisdicción especial creada por el Marco Jurídico para la Paz; y, por otra, fijar los casos que, al no ser conocidos por la jurisdicción especial creada por la justicia transicional, deben ser enviados a la jurisdicción ordinaria para su investigación y juzgamiento.

Esta exposición realizada sobre los elementos del modelo argumentativo empleado por el experto invitado, Alejandro Aponte, devela el modo causal de la aserción, el talante normativo de los soportes de la aserción, el carácter reivindicador y regulador del principio y de las reglas respectivamente que garantizaron la conexión aserción-datos, la manera dogmática de los conceptos jurídicos que respaldan dichas garantías, la fuerza de alto grado de certeza inyectada a la aserción por la expresión modal "imposible", y la naturaleza de la refutación centrada en el reconocimiento de que los casos no seleccionados

17 Cursivas nuestras de acuerdo con los fines establecidos en el artículo.

18 Aponte (2013), p. 7. 
deben ser investigados y juzgados por la jurisdicción ordinaria. Modelo que fue empleado con la intención de confirmar la constitucionalidad del Acto Legislativo 01 de 2012, dado que está conforme con las obligaciones emanadas de los instrumentos internacionales sobre derechos humanos aceptados por el Estado colombiano mediante su ratificación. Confirmación que allana el camino para legitimar un sentido de justicia transicional que flexibiliza el ordenamiento jurídico-penal. Lo cual evitaría el colapso del sistema de justicia que ordinariamente no puede dar cuenta de la totalidad de hechos constitutivos de delitos en la sociedad y máxime cuando se trata de casos relacionados con violaciones sistemáticas de los derechos humanos y el DIH.

b) La tesis de los magistrados de la Corte Constitucional consistió en declarar la exequibilidad del inciso cuarto del artículo 1 del Acto Legislativo 01 de 2012, en los términos señalados en la Sentencia C-579 de 2013. Tesis de tipo definitorio al establecer que el inciso $4^{\circ}$ es Constitucional. Esta aserción fue apoyada a partir de las siguientes evidencias: 1) las expresiones demandadas consagran la posibilidad de utilizar los criterios de selección y priorización para investigar, juzgar y sancionar los crímenes más graves contra los derechos humanos y el DIH cometidos por los máximos responsables, así como también establecen la eventualidad de renunciar a la persecución penal de los demás casos no seleccionados; además de estos dos criterios dicho inciso contempla todo un sistema complejo de justicia transicional. 2) Los demandantes sostienen que con el Acto Legislativo se sustituye uno de los pilares de la Constitución razón por la cual la Corte Constitucional ha de realizar un juicio de sustitución.

Para unir dicha tesis definitoria con las evidencias descriptas se acudió al principio de unidad normativa y a la metodología del juicio de sustitución. El principio de unidad exige que para poder analizar la exequibilidad de las expresiones demandadas se debe efectuar una integración normativa: tener en cuenta todos los instrumentos que conforman el sistema de justicia transicional instituido a través del Acto Legislativo demandado. Y la metodología del juicio de sustitución refiere a la necesidad de realizar un test de sustitución que tiene la forma de un silogismo: la premisa mayor es el elemento esencial que se alega sustituido, la premisa menor es el contenido y alcance de la reforma constitucional acusada, la conclusión emerge de la confrontación de la premisa menor con la mayor ${ }^{19}$.

Para darle fuerza de validez a estas dos garantías, los magistrados acudieron a dos tipos de respaldos: 1) finalidad del principio de la unidad normativa, y 2) dos presupuestos dogmáticos. El primer respaldo admite la necesidad de evitar la generación de una situación de incertidumbre sobre el contenido armónico e

19 Corte Constitucional (2013), Sentencia C-579, consideraciones 5.2. 
integrado de la norma legal objeto de análisis; pues no llevar a cabo la unidad normativa podría producir una interpretación incoherente o inaplicable del contenido de la norma. El segundo tipo de respaldo privilegia, en un primer momento, la premisa de que la justicia transicional no constituye per se una sustitución de la Constitución, pues armonizar la satisfacción de los derechos de las víctimas con el logro del cese de hostilidades hace parte tanto de los propósitos de la justicia transicional como de los principios constitucionales; y acepta, en un segundo momento, el presupuesto dogmático que demanda examinar la probabilidad de sustitución o no del pilar fundamental de la Constitución al institucionalizarse el inciso $4^{\circ}$, mediante la ponderación.

Acorde con dichos elementos expuestos, los magistrados de la Corte Constitucional articularon en su modelo argumentativo un cualificador modal y una posible refutación. El cualificador modal está representado en la expresión "en los términos señalados ${ }^{20}$ en esta sentencia" ${ }^{21}$; es decir, el grado de intensidad del cualificador que se empleó es moderado. Y la posible refutación se pone de relieve cuando los magistrados de la Corte advierten que el modo "como están redactadas las expresiones demandadas puede dar lugar a algunas interpretaciones cuya aplicación en la ley estatutaria o en otras formas de implementación del Acto Legislativo pueden conllevar a la anulación o el desconocimiento de la obligación de garantía de investigar, juzgar y en su caso sancionar las graves violaciones a los Derechos Humanos y al Derecho Internacional Humanitario"22.

En síntesis, la anterior descripción sobre el modelo argumentativo usado por los magistrados de la Corte Constitucional deja ver un tipo de aserción definitoria, dos clases de evidencias que están representadas en un criterio normativo y en una manera de aplicación de normas, dos garantes que reivindican un principio de unidad normativa y un juicio de sustitución, dos respaldos que aluden a la finalidad del principio de la unidad normativa y a presupuestos dogmáticos, un cualificador modal de grado moderado, y una refutación en la que se advierte la posibilidad de una interpretación no ajustada a los estándares de los derechos humanos y del DIH. Unos y otros elementos configuran el modelo argumentativo empleado para legitimar la exequibilidad del inciso $4^{\circ}$, artículo 1, Acto Legislativo 01 de 2012. Declaración de exequibilidad que valida el marco constitucional en virtud del cual se debe llevar a cabo el proceso de paz entre el Estado colombiano y las FARC-EP y, al mismo tiempo, se privilegia un sentido de flexibilización de justicia transicional. Este sentido encuentra su

20 Cursivas nuestras.

21 Corte Constitucional (2013), Sentencia C-579, resuelve.

22 Corte Constitucional (2013), Sentencia C-579, consideraciones, juicio de sustitución, 8.4. 
fundamento en la necesidad de limitar el pilar de la Constitución según el cual es deber del Estado investigar, juzgar y, si es el caso, sancionar a los responsables de graves violaciones a los derechos humanos y al DIH. Lo que se constituye en condición esencial para lograr el cese efectivo de las hostilidades dentro del conflicto armado en Colombia.

\section{Conclusión}

De acuerdo con las descripciones realizadas a lo largo del presente artículo se logró presentar, en línea con el modelo argumentativo de Toulmin, los elementos y sus características que conforman algunos de los modelos argumentativos usados en la discusión realizada en Colombia sobre la constitucionalidad del inciso $4^{\circ}$, del artículo 1 del Acto Legislativo 01 de 2012; discusión que culminó en la declaración de exequibilidad de dicho inciso en la Sentencia C-579 de 2013.

La primera descripción permitió dar cuenta de los elementos y características que constituyen a los modelos argumentativos empleados por algunos de los defensores de la inexequibilidad: demandantes y experta invitada de Amnistía Internacional. Respecto a los demandantes se encontró que el modelo fue empleado con la intención de posicionar un sentido normativo de la justicia transicional y desplazar el sentido de flexibilización ennoblecido por los promotores de la constitucionalidad del Acto Legislativo 01 de 2012. Este sentido de flexibilización abre la puerta para sustituir el pilar fundamental consistente en el compromiso estatal de investigar, juzgar y eventualmente sancionar a quienes han vulnerado de manera grave los derechos humanos y el DIH. Apertura que coloca en un segundo plano este pilar fundamental de la Constitución de 1991, generando así como consecuencia el detrimento de la dimensión dogmática de la Constitución. Lo cual conlleva a la pérdida de legitimación del orden sociojurídico colombiano, pues niega el principio de justicia. Y en lo relativo a la experta invitada de Amnistía Internacional, Guadalupe Marengo, se halló que el modelo argumentativo fue utilizado para dejar constancia de que si se acoge cualquier criterio que admita renunciar a la persecución penal de graves violaciones de derechos humanos en el marco de una justicia transicional, se desconocen las obligaciones de derecho internacional derivadas de los convenios en los que Colombia es un Estado Parte. Constancia que está en correspondencia con la legitimación de un sentido normativo de la justicia transicional.

La segunda descripción facilitó poner de relieve los elementos y características que configuran los modelos argumentativos usados por ciertos promotores de la exequibilidad del inciso en cuestión: Alejandro Aponte como experto invitado y magistrados de la Corte Constitucional colombiana. En lo referente al experto invitado se encontró que el modelo argumentativo fue utilizado para ratificar la constitucionalidad del Acto Legislativo 01 de 2012, pues el experto afirmó 
que tal Acto está en armonía con los compromisos adquiridos por el Estado en el marco del derecho internacional. A través de esta aseveración se intentó legitimar un sentido de flexibilización de la justicia transicional orientado hacia la relativización del ordenamiento jurídico-penal. Lo cual presupone reconocer los límites del sistema penal, en casos de violaciones sistemáticas de los derechos humanos, como exigencia ineludible para la conservación del sistema de justicia penal. Y en lo pertinente a los magistrados de la Corte Constitucional se evidenció que el modelo argumentativo fue usado con el fin de declarar la constitucionalidad del Acto Legislativo en cuestión, reivindicando un sentido de flexibilización de justicia transicional condicionado por la interpretación trazada en la Sentencia C-579 de 2013. La consecución de la paz en el contexto del conflicto armado colombiano exige limitar uno de los pilares constitucionales: el deber del Estado investigar, juzgar y, si es el caso, sancionar a los responsables de graves violaciones a los derechos humanos. Lo cual es urgente para realizar de manera efectiva el proceso de diálogo y poner en marcha los acuerdos a los que eventualmente lleguen las partes en conflicto.

Finalmente, apoyados en estos resultados se puede inferir ahora que en el intento de solución de la tensión entre el principio de la justicia y el principio de la paz $^{23}$, los actores emplearon modelos argumentativos orientados por dos sentidos diferentes de justicia transicional. Mientras el primero posibilitó ennoblecer un sentido normativo en el que se otorga preeminencia al principio de la justicia sobre la paz, el segundo modelo permitió enaltecer un sentido flexibilizador en virtud del cual se concede preferencia al principio de la paz sobre la justicia. Estos dos sentidos opuestos se apoyan en argumentaciones provenientes, respectivamente, de la jurisprudencia nacional e internacional. No obstante, quienes dignificaron un sentido normativo de la justicia transicional acudieron a un enfoque prescriptivo que antepone al Estado la necesidad de investigar, juzgar y eventualmente sancionar todos los casos de vulneraciones graves a los derechos humanos como condición ineludible para la consolidación del Estado social y democrático de derecho; exigencia que presupone que los casos no seleccionados dentro del marco de la justicia transicional deben ser remitidos a la justicia ordinaria, pues no es posible renunciar a la persecución penal frente a este tipo de delitos. Y quienes honraron un sentido de flexibilización de la justicia transicional recurrieron a una perspectiva contextual que reconoce la importancia de aplicar la justicia acorde con las circunstancias actuales del conflicto interno y la pretensión de la culminación negociada del mismo; contextualización que admite relativizar el sistema ordinario de justicia frente a la violación de derechos humanos y potenciar de este modo la

23 UPRIMNy (2006), p. 13. 
actualización de ese sistema en línea con las circunstancias jurídico-políticas actuales de la sociedad colombiana.

\section{BiBLIOGRAFÍA CITADA}

Alexy, Robert (1997): Teoría de la argumentación jurídica (Madrid, Centro de Estudios Constitucionales).

AmNisTía INTERNACIONAL (2013): Concepto en calidad de experta invitada, en: Expediente D-9499, Relatoría de la Corte Constitucional de Colombia, folios 387-393.

Aponte Cardona, Alejandro (2013): Concepto en calidad de experto invitado, en: Expediente D-9499, Relatoría de la Corte Constitucional de Colombia, folios 343-347.

AtienzA, Manuel (2005): Las razones del derecho. Teorías de la argumentación jurídica (D.F. México, Universidad Nacional Autónoma de México).

COMISIÓN COlOMBIANA DE JURISTAS (2012): Demanda de inconstitucionalidad contra el acto legislativo 01 de 2012 (parcial), en: Expediente D-9499, Relatoría de la Corte Constitucional de Colombia, folios 36.

Pastor Ridruejo, José Antonio (1994): Curso de derecho internacional público y organizaciones internacionales (Madrid, Tecnos).

Perelman, Chaim y OlbreChts-TyteCA, Lucie (1989): Tratado de la argumentación. La nueva retórica (Madrid, Editorial Gredos).

Toulmin, Stephen E. (2007): Los usos de la argumentación, segunda edición (Barcelona, Ed. Península).

UPRIMNY, Rodrigo (Director) (2006): ¿justicia transicional sin transición? (Bogotá, Centro de Estudios de Derecho, justicia y Sociedad).

\section{JURISPRUDENCIA CITADA}

Caso Velásquez Rodríguez vs. Honduras (1988): Corte Interamericana de Derechos Humanos, Fondo, Sentencia de 29 de julio.

Sentencia C-579 de 2013, Corte Constitucional de Colombia, M.P. Jorge Ignacio Pretelt Chaljub.

\section{NORMAS JURÍDICAS CITADAS}

Congreso de la República de Colombia (2012), Acto Legislativo 01.

Constitución Política de Colombia (1991). 